\title{
Serving the professional staff in higher education
}

\author{
By Sherman Hayes
}

Library Director

Bentley College

\section{Should it be a bigger part of your mission?}

A $s$ the roles and functions of teaching and research faculty along with other aspects of higher education have changed over recent years, there has been an increase in the sophistication and number of professional staff in higher education. Their information needs have correspondingly increased. In academic libraries, the traditional client mix has been primarily composed of faculty and students. While not recommending a major change from that priority, I do want to raise the question of whether or not your library could and should serve your institution's staff at a high level. Who is this staff and why do they have increasing information needs; what is characteristic of these needs; and what supplemental methods using existing collections and resources could better serve these important potential or existing clients?

A recent U.S. Employment Opportunity Commission study found that those employed to perform academic support functions in higher education who were not part of the teaching faculty increased by more than $60 \%$ between 1975 and $1985 .^{1}$ Reasons for the increase in academic support personnel and other areas of the institution go beyond the changing nature of faculty. Some of the high growth areas in higher education professional

1"Big Increases in Academic-Support Staffs Prompt Growing Concerns on Campuses" The Chronicle of Higher Education, March 28, 1990, pp. Al, A32-34. staff are mentioned below. As you review this incomplete brief list of some job titles and functions, think of the people you know in these positions.

More people are needed now to help an institution comply with federal and state regulations in specific areas such as safety, hazardous waste, energy efficiency, handicapped access, and affirmative action. As the student population changes, roles of counselors, tutors, advisors, and student services support shift increasingly to nonfaculty positions. The explosion in computing power applies to almost every phase of higher education and requires a large number of technical and professional level specialists. For example, even with the increased sophistication and knowledge in computing that librarians have acquired, we still call on programmers, systems designers, machine operators, and repair technicians for help.

Another area of staff growth in almost every higher education institution is in activities related to fundraising, development, and grants operations. Grants may create a set of professionals, separate from faculty, who are researchers or assistants or clinicians, writers or artists in residence supporting these operations. Core administrative services such as personnel, planning, legal services, purchasing, and financial services need better information to function. My Cook's tour concludes with the recognition that our buildings, whether old and in need of repair or new and expanding, are planned, serviced, and supported by a group of employees who are called on to do more with less in 
the rapidly expanding technological arena known as physical plant operations.

An analysis of this highly varied group reveals some interesting patterns pointing to the strong information needs required to do their jobs well. These people are highly educated, as evidenced by the many master's and Ph.D. degrees in their ranks. Frequently, they are narrow specialists requiring very specific current information and, because they are oriented to information, media and technology, computing is a daily part of their work and world. They belong to professional organizations and participate in professional activities. Many people write and publish in their discipline. They may be pursuing degree programs or attending continuing education workshops. Perhaps most important is this group's hunger for information and resources that the library can provide to help them keep up with their jobs and the changing work and personal environment.

There are compelling reasons to review your services to staff and consider ways to increase assistance beyond the fact that there are so many more of them! First, my philosophy is that it is better to have services and collections that are used than to let them stand idle. If you expend resources to purchase journals and books for research and the curriculum, it is more "profitable" to have these materials used by anyone and everyone in the academic community and provide a "higher return on the library investment." The use of many of these services and collections can be increased without creating conflict between competing clients.

A second logical reason to work with staff is that they are your colleagues and either provide their services to your library now or may in the future. If the library is only a taker in its relationship with physical plant, human resources or other operations, it has less effective power to change the service delivery patterns of others or ask for unusual assistance in the future. If companion operations use you at some level important to them, they will have a better understanding of your services and your requests for support and resources.

Speaking of resources, I don't know about your institution, but at every one for which I have worked, it was ironic that the two primary groups served (faculty and students) have almost no influence or direct impact on the funding of our operation through the budget process. The very people who say yes or no to our future (academic administration, financial administration, presidents and trustees) are seldom heavy users of the library and neither need nor understand our services as much as faculty and students.

Finally, you can help support your faculty and students by assisting those who serve them in different capacities. One cannot shift priorities to assist staff audiences exclusively or inappropriately, but it would not hurt if they used your services at a helpful level and realized that your continued health enhances their purposes and those of the entire institution.

Having identified this growing sophisticated group, let's discuss the critical issue of servicing them and how much service to provide. Each library must address this as a local issue. I propose that discussing and analyzing the level of service that should be provided to this group is a useful proactive (rather than reactive) exercise and a first step to take in your academic community. Of course I think libraries should continue to perform their mission as the primary information, instruction and research support unit for faculty and students. No other institution on campus is charged with this important task. In an age of decreasing resources, one needs to be careful about moving away from core service requirements to serve a less central patron. Faculty and students are possessive about our services, and we should take care not to place service to staff in conflict with our core clientele to make the core feel that we have chosen someone else as our "preferred customer."

However, even as we protect and expand services to core clients, there should still be many ways to assist staff using existing services and collections that will not significantly change assistance to faculty and students. This core group of patrons does need to be reminded, however, that service to staff, who in turn serve faculty and students, should not take anything away from them or the institution. If the Development Office succeeds, we are all better off. If the Registrar makes registration less painful with the library's help, students are better served. If the Counseling Office finds the perfect journal article in the library to better fill a student need, we have helped that student too.

Our experience indicates that staff professionals recognize the library's priority for faculty and student interests. Since many of our information services are not current enough or specialized enough for their needs, they have created an information network separate from the library to meet their very pressing requirements. However, they are still very interested in supplemental assistance and information identification that they may have missed in support of their work.

If you agree that this group is an important potential growth area for assistance, the next step is to review your current service levels for professional staff and determine how you could possibly work with them at a different level in the future. Perhaps an anecdotal review of some of our popular services used heavily by staff in our institution would be helpful.

Our journal collection experiences the most use. We make a complimentary table of contents serv- 
ice available to all faculty and staff. The three hundred participants select the journal contents they want to see. Acting as their agent, we intercept new journals, make copies of contents based on their customized request profiles and forward the contents to them each month. While journals originally were and continue to be selected to provide curriculum and research support, we find that $40 \%$ of the participants in the service are staff members. Even though most of them take other periodicals of a more specific nature through their offices or at home, they want to know more about a wide variety of subjects and use this service to keep up.

We also offer article copy service in connection with the table of contents service. Some of our heaviest users are in the Placement Office, Student Services, and Counseling Center. They feel that the convenience of the combined service allows them to maintain professional currency when their schedules do not permit them to come to the Library as often as they would like.

Database searching and other reference services are heavily used by several areas. Our Development Office looks for background information on potential donors. The President's office often seeks answers to data questions and bibliographic citation support. Of course we always recommend that a library help the President's office with whatever they want! If your library has legal materials to support courses as we do, the staff that wrestles with the many legal questions raised in higher education is very grateful for the collection and assistance.

Educational materials purchased for faculty can be very helpful to academic administration planners as well. We get equal amounts of use of educational materials from both staff and faculty. ERIC is in demand by research associates in the Planning Office, Admissions and the Dean of Faculty's office.

Your library may be like ours in that it also functions like a public library for students. Since we are not very near our local public library, we purchase some current fiction and literature as popular reading. Our Admissions Office recruiters and other staff members who travel regularly have discovered this collection and use it heavily. Their comfort level in using this and other services helps them explain our operations more accurately to outside contacts.

Part of the array of services we provide on campus is media services. Although the media staff works very hard to keep academic business as first priority, they assist other units when time and energy permit. They have produced training and other video tapes for Affirmative Action, Purchasing, and Admissions. Our Graphics Producer has advised or produced materials for the Finance Office, Development, and the Board of Trustees.
Media delivery personnel assist many groups on campus with technical AV presentations.

Archives is a standard library function that, in many ways, serves non-traditional groups more than present faculty and students. Archives has ongoing relationships with Development, Alumni, the President's Office, and many other campus units. Interlibrary loan has proven to be a lifesaver for staff just as for students and faculty.

I assume that you too, whether you realize it or not, serve the professional staff in many ways. Just as you have systematically looked for new and improved ways to better assist faculty and students as your primary patrons, it may be a logical strategy to examine ways you can and should most effectively be serving the staff in higher education. Have you taken an inventory of which staff use your library? Do you have specific library staff who are charged with supporting the subject areas of "staff interests" just as you might have librarians working with the humanities departments? Does your library staff know the names and functions of other staff on your campus? Do you have alert systems notifying staff of new acquisitions and services just as you do for faculty?

If you were to choose to serve this patron group at a newer, higher level, there may well be conflicts related to resources available, priorities, increased work loads, and differences in perception of timeliness of information needed, to name a few. However, it is important to note that working with this group offers new opportunities to utilize what you already have in place, affords new bridges of cooperation with other campus service units, supplies indirect ways to support your primary mission of service to faculty and students, and puts you in contact with a group of people who really do need and want your services.

\section{5\% rate Choice the best for academic book reviews}

In a recent commissioned study of Choice subscribers, $95.7 \%$ responded that Choice provides the best coverage of academic books. Out of a group of national review journals, respondents picked Choice as the publication with the most complete reviews, the best reviews written by experts and the reviews that are most to the point.

Choice commissioned Research USA to profile the readers of Choice to determine how the magazine is read and how it influences selection. $74.1 \%$ of the respondents reported that Choice is one of the several major sources of information that influence the purchase of print and nonprint titles. For further information, contact Sabosik at (203) 347-6933. 